\section{Short-term effects of topical cyclosporine A $0.05 \%$ (Restasis) in long-standing prosthetic eye wearers: a pilot study}

JW Han ${ }^{1}$, JS Yoon ${ }^{2}$ and SY Jang ${ }^{1}$

${ }^{1}$ Department of Ophthalmology, Soonchunhyang University Bucheon Hospital, Soonchunhyang University College of Medicine, Bucheon, Korea

\section{Department of} Ophthalmology, Severance Hospital, Institute of Vision Research, Yonsei University College of Medicine, Seoul, Korea

Correspondence:

SY Jang, Department of Ophthalmology,

Soonchunhyang University Bucheon Hospital, Soonchunhyang University College of Medicine, 170 Jomaru-ro, Wonmi-gu, Bucheon 420-767, Korea Tel: +82 326216718 ; Fax: +82 326215018 . E-mail: ysyat01@ naver.com

Received: 23 January 2014 Accepted in revised form: 20 May 2014

Published online: 1 August 2014

\begin{abstract}
Purpose Long-standing prosthetic eye wearing induces ocular surface inflammation. We investigated the short-term effects of topical cyclosporine A $0.05 \%$ (Restasis) in patients with ocular discomfort resulting from long-standing prosthetic eye wearing. Methods This was a prospective, interventional case series. Patients who were unilateral prosthetic eye wearers over a period of 5 years were enrolled at a single institution from March to July 2013. The subjects were instructed to instill topical cyclosporine A $0.05 \%$ twice per day. Measurements were made pre-treatment and after 1 and 3 months of treatment. Outcome measures were the ocular symptom score, the lid margin abnormality score, the Schirmer test, and the tear meniscus amount, using Fourier-domain optical coherence tomography.

Results In total, 20 consecutive patients (mean age: 60.1 years, 8 males, 12 females) were included. Ocular symptoms were improved after treatment for 1 month in all patients (ocular symptom score pre-treatment 76.83 vs 46.75 after treatment; $P<0.001$ ). There was no statistically significant difference in lid margin abnormality score or tear meniscus amount. The Schirmer test results were improved after treatment for 3 months (pre- and after treatment, $6.70 \mathrm{vs}$ 11.40; $P<0.001)$.

Conclusions Topical cyclosporine A $\mathbf{0 . 0 5 \%}$ showed a satisfactory effect in long-standing prosthetic eye wearers. Ocular symptoms were markedly relieved in all subjects after treatment for 1 month.
\end{abstract}

Eye (2014) 28, 1212-1217; doi:10.1038/eye.2014.174; published online 1 August 2014

\section{Introduction}

Patients wearing prosthetic eyes often complain of dryness, irritation, discomfort, and discharge. Indeed, there have been questionnaire-based investigations that reported that most prosthetic eye wearers are concerned about eye watering, crusting, and discharge. ${ }^{1,2}$ Several studies have investigated the cause(s) of ocular discomfort in prosthetic eyes wearers. ${ }^{3}$ Allen et $a l^{4}$ suggested that most patients with anophthalmic socket have tear insufficiency and this may be a major cause of discomfort in these patients. In clinics, many prosthetic eye patients with ocular discomfort are prescribed artificial lubricants to relieve their ocular symptoms. However, some patients still continue to experience discomfort, even though they use artificial lubricants continuously over the long term.

Cyclosporine A $0.05 \%$ is a topical immunomodulatory compound with antiinflammatory properties that has been demonstrated to have certain benefits in the treatment of dry-eye symptoms. ${ }^{5}$ Indeed, many clinical studies have found good results with topical cyclosporine A $0.05 \%$ treatment for dry-eye syndrome, through modulating ocular surface inflammation. ${ }^{6}$

To our knowledge, there is no reported study regarding the use of cyclosporine A $0.05 \%$ to treat patients with ocular prostheses who have dry eye symptoms or inflamed ocular surfaces. Thus, in the present study, we evaluated the effectiveness of treatment with cyclosporine A $0.05 \%$ in long-standing prosthesis wearers with 
ocular discomfort. We analyzed changes before and after cyclosporine A $0.05 \%$, assessing Schirmer test results, tear meniscus amounts, lid margin abnormalities, and ocular symptom scores.

\section{Materials and methods}

\section{Patients}

In total, 20 patients with unilateral ocular prostheses for more than 5 years who visited Bucheon Soonchunhyang University Hospital between March 2013 and July 2013 were the subjects. Patients who had lid abnormalities, such as ectropion or entropion, were excluded. Patients who had socket problems, such as implant exposure or sac contracture, were also excluded. One of the authors (SYJ) prescribed cyclosporine A $0.05 \%$ (Restasis) to the subjects. All patients were advised to take one drop of cyclosporine A $0.05 \%$ twice per day for 3 months. The patients continued the treatment process over at least 3 months. They were asked questions regarding their demographic status and duration of eye prosthesis use. Furthermore, to assess the causes of ophthalmic surgery and type of surgery, such as evisceration or enucleation, we reviewed the chart of each patient.

This study adhered to the principles of the Declaration of Helsinki and was approved by the Institutional Review Board of Soonchunhyang University Hospital. Informed consent was obtained from all participants. Patients who did not agree to participate were excluded.

\section{Outcome measures}

A standard Schirmer test was performed on the prosthetic eyes at three points: (1) before the start of topical cyclosporine A $0.05 \%$, (2) after 1 month of use, and (3) after 3 months of use. Sterile strips of filter paper were placed in the temporal one-third of the lower lid before closing the eyes for $5 \mathrm{~min}$. Then, strips were removed and the lengths of the wet portion were measured (in $\mathrm{mm}$ ) to determine the Schirmer test value.

Ocular symptoms, score measurements, and eyelid margin assessments were determined as described by Jang et al. ${ }^{7}$ Ocular symptoms were assessed using a fivepoint categorical scale: none (0), some of the time (1), half of the time (2), most of the time (3), and all the time (4). Patients were asked to assign the severity of their symptoms using this scale before the start, and after using topical cyclosporine A $0.05 \%$ for 1 and 3 months. Patients reported the frequency of symptoms related to dry eyes, such as ocular fatigue, discharge, foreign body sensation, pain, tearing, itching sensation, burning sensation, heavy sensation, excessive blinking, uncomfortable in windy conditions, and uncomfortable in very dry conditions.
Each individual symptom score was added up, for a possible range between 0 and 60 points. We then converted the numbers to a score out of 100 .

Eyelid margin abnormalities were scored to assess four items: lid margin irregularity, telangiectasis, mucocutaneous anterior displacement, and plugged orifices. Slit lamp examinations were used to assess the lid margin. If any of these signs were present, one point was assigned for each, with a total possible score range of 0-4 points. Lid margin abnormalities were also checked before the start and after using topical cyclosporine A $0.05 \%$ for 1 and 3 months.

Tear meniscus amount measurements were made as described by Kim et al. ${ }^{8}$ A high-speed, high-resolution, Fourier-domain optical coherence tomography (FD-OCT) device (RTVue; Optovue Inc., Fremont, CA, USA) was used to measure the tear meniscus height, depth, and angle; results were obtained using computer calipers. The tear meniscus area was calculated using a formula based on a triangular approximation (tear meniscus area $=0.5 \times$ tear meniscus height $\times$ tear meniscus depth). FD-OCT was performed before the start and after using topical cyclosporine A $0.05 \%$ for 1 and 3 months. OCT settings remained constant throughout the experiment for all subjects.

\section{Data analysis}

The PASW software (ver. 19.0; IBM Corp., Armonk, NY, USA) was used for data analysis. Wilcoxon's signed rank test was used to compare ordinary categorical variables, such as the Schirmer test, lid margin abnormality scores, tear meniscus amounts, and ocular symptom scores.

\section{Results}

In total, 20 patients ( 8 males, 12 females) who had used an ocular prosthesis for longer than 5 years were treated with topical cyclosporine A $0.05 \%$, one drop twice per day. Treatment was well tolerated, and no patient discontinued the study because of adverse events.

Patient demographic characteristics are summarized in Table 1 . The mean patient age was $60.11 \pm 20.10$ (range, 26-95) years and the mean duration of prosthesis usage was $10.89 \pm 5.18$ (range, 5-25) years. The most common cause of ophthalmic surgery was trauma $(50 \%)$ and evisceration was the most common type of eye removal surgery (65\%).

The mean ocular symptoms score with an ocular prosthesis at baseline before the start of topical cyclosporine A $0.05 \%$ was $76.83 \pm 8.73$. The mean ocular symptoms scores after treatment for 1 and 3 months were $54.37 \pm 9.47(P<0.001)$ and $46.75 \pm 10.81(P<0.001)$, respectively (Figure 1a). There was significant improvement in the ocular symptoms score after 1 month 
Table 1 Patient demographics

\begin{tabular}{lc}
\hline Demographic & Score \\
\hline Total $(n)$ & 20 Patients \\
Age: years, mean \pm SD (range) & $60.11 \pm 20.10$ (26-95 Years) \\
Duration of prosthesis use: years, & $10.89 \pm 5.18$ (5-25 Years) \\
mean \pm SD (range) & \\
Gender & \\
Males & 8 \\
Females & 12 \\
& \\
Cause of blindness: number of patients (\%) & $10(50.0 \%)$ \\
Trauma & $6(30.0 \%)$ \\
Disease & $1(5 \%)$ \\
Congenital & $3(15 \%)$ \\
Unknown & \\
Operation type: number of patients (\%) & $13(65 \%)$ \\
Evisceration & $5(25 \%)$ \\
Enucleation & $2(10 \%)$ \\
Unknown &
\end{tabular}

of cyclosporine A $0.05 \%$ treatment $v$ s baseline $(P<0.001$; Table 2). For the symptoms listed in Table 3, all symptoms except excessive blinking showed significant improvements after 3 months of cyclosporine A 0.05\% treatment.

The mean Schirmer test result before the start of topical cyclosporine A $0.05 \%$ was $6.70 \pm 2.96 \mathrm{~mm}$. The mean Schirmer test results after 1 and 3 months of treatment were $7.10 \pm 3.16(P=0.149)$ and $11.40 \pm 2.46(P<0.001)$, respectively (Figure $1 \mathrm{~b}$ ). No significant difference was observed in the Schirmer test between the 1-month result and the initial evaluation $(P=0.149)$. However, significant improvement was observed at 3 months compared with that at the initial evaluation $(P<0.001$; Table 2).

The mean lid margin score before using topical cyclosporine A $0.05 \%$ was $1.10 \pm 0.91$. The mean lid margin scores after treatment for 1 and 3 months were $0.95 \pm 0.76(P=0.180)$ and $0.85 \pm 0.67(P=0.096)$, respectively. No significant changes were observed among the three values (Table 2).

Of the four criteria in Table 4, there was no significant change in the mean tear meniscus height, tear meniscus angle, or tear meniscus area after treatment for 1 or 3 months. In the case of tear meniscus depth, however, there was a significant improvement after cyclosporine A $0.05 \%$ treatment for 3 months $(P=0.019$; Table 4$)$.

\section{Discussion}

Cyclosporine was originally developed to prevent solid organ graft rejection. ${ }^{9}$ In 1989, Kaswan et al ${ }^{10}$ first reported that topical cyclosporine was effective in the treatment of dry eye in dogs that had developed keratoconjunctivitis sicca. Since then, topical a

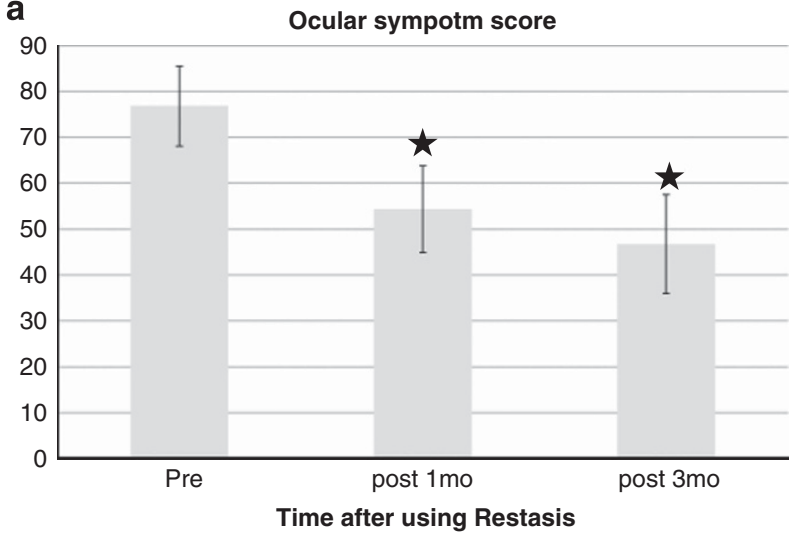

b

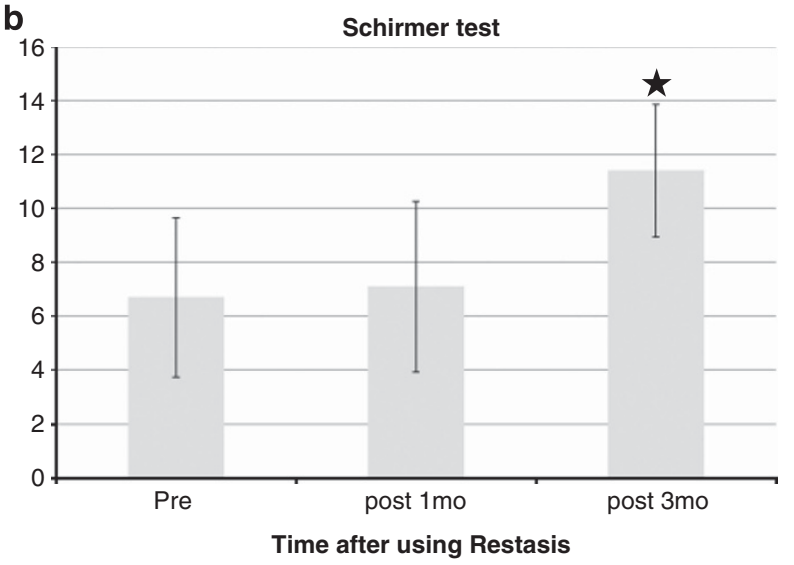

Figure 1 (a) Ocular symptom score at baseline and after treatment with cyclosporine A $0.05 \%$ (Restasis) twice per day. The decrease from baseline was statistically significant at 1 and 3 months $(P<0.05)$. (b) Schirmer test at baseline and after treatment with cyclosporine A $0.05 \%$ (Restasis) twice per day. The increase from baseline was statistically significant at 3 months $(P<0.05)$. ${ }^{\star}$ Significant change compared with first visit.

cyclosporine A $0.05 \%$ has been shown to be effective in the treatment of several ocular surface diseases, including vernal keratoconjunctivitis, ${ }^{11}$ immunemediated keratitis, ${ }^{12}$ necrotizing scleritis, ${ }^{13}$ and corneal allograft rejection. ${ }^{14}$ There have been several clinical trials investigating the effect of cyclosporine in dry eye patients. ${ }^{15-17}$ In one, cyclosporine significantly reduced conjunctival Rose Bengal staining, superficial punctuate staining, and ocular irritation symptoms. Cyclosporine has been shown to decrease activated T cells, ${ }^{15}$ pro-inflammatory cytokines, ${ }^{18,19}$ and epithelial cell apoptosis, ${ }^{20}$ and to increase goblet cell density in dry eye with an inflammatory component. ${ }^{21}$

In the present study, we investigated the short-term effects of cyclosporine $\mathrm{A}$ in patients with ocular discomfort resulting from long-standing prosthetic eye use. An anophthalmic socket has a different anatomical and physiological environment, as compared with a normal eye. It is characterized by the absence of a cornea 
Table 2 Schirmer test, lid margin abnormality score, and ocular symptom score at baseline and after treatment with cyclosporine A $0.05 \%$ (Restasis) twice per day for 3 months

\begin{tabular}{|c|c|c|c|}
\hline & First visit & After 1 month & After 3 months \\
\hline \multicolumn{4}{|l|}{ Shirmer test } \\
\hline Average & $6.70 \pm 2.96$ & $7.10 \pm 3.16$ & $11.40 \pm 2.46$ \\
\hline$P$-value & & 0.149 & $<0.001^{*}$ \\
\hline \multicolumn{4}{|c|}{ Lid margin abnormality score } \\
\hline Average & $1.10 \pm 091$ & $0.95 \pm 0.76$ & $0.85 \pm 0.67$ \\
\hline$P$-value & & 0.180 & 0.096 \\
\hline \multicolumn{4}{|c|}{ Ocular symptom score } \\
\hline Average & $76.83 \pm 8.73$ & $54.37 \pm 9.47$ & $46.75 \pm 10.81$ \\
\hline$P$-value & & $<0.001^{*}$ & $<0.001^{*}$ \\
\hline
\end{tabular}

Data were analyzed using the Wilcoxon signed-rank test ${ }^{*} P<0.05$ is considered statistically significant). The $P$-value was calculated for the data from the first visit compared with the visit after 1 month, and the visit after 3 months.

and by continuous mechanical rubbing between the socket and prosthetic eye. As cyclosporine is known to be an effective treatment for controlling ocular surface inflammation, we hypothesized that topical cyclosporine might be effective for the relief of ocular symptoms resulting from the different environments in anophthalmic patients. In this study of subjects with prosthetic eyes, most symptoms showed improvement after 1 month of cyclosporine A $0.05 \%$ treatment. All patients showed satisfaction in terms of ocular symptom relief. Furthermore, there were statistically significant improvements in the Schirmer test after 3 months of cyclosporine A $0.05 \%$ treatment.

Prosthetic eye wearers tend to suffer from blepharitis and meibomian gland dysfunction. This is well documented in a recent report by Jang et al. ${ }^{7}$ It has been suggested that meibomian gland dysfunction can be treated effectively with cyclosporine A $0.05 \% .{ }^{22-24}$ The ocular prosthesis causes mechanical trauma to the tarsal conjunctiva, thus altering the meibomian gland structure. ${ }^{3,25}$ Furthermore, poor hygiene with the prosthetic eye can lead to inflammation of the anophthalmic socket. Discharge from inflammation of anophthalmic socket can also cause meibomian gland obstruction. Obstruction of the meibomian ducts can then cause accumulation of meibum, which may lead to inflammation and bacterial colonization. ${ }^{26-29}$ These conditions may cause clinically apparent ocular discomfort to prosthetic eye wearers. Inflammatory cytokines, such as interleukin (IL)-1, IL-6, IL-8, IL-12, and epidermal growth factor, have been reported to be increased in patients with meibomian gland dysfunction. ${ }^{30,31}$ Thus, topical cyclosporine A $0.05 \%$, as a specific immunomodulator acting on $\mathrm{T}$ cells, may decrease the inflammation in meibomian gland dysfunction and improve the ocular symptoms.
Table 3 Ocular symptom score before and after treatment with cyclosporine A $0.05 \%$ (Restasis) twice per day for 3 months

\begin{tabular}{|c|c|c|c|}
\hline & First visit & After 1 month & After 3 months \\
\hline \multicolumn{4}{|c|}{ Ocular fatigue } \\
\hline Average & $3.07 \pm 0.92$ & $1.21 \pm 0.95$ & $0.57 \pm 0.64$ \\
\hline$P$-value & & $0.01^{*}$ & $0.01^{*}$ \\
\hline \multicolumn{4}{|l|}{ Discharge } \\
\hline Average & $2.92 \pm 0.92$ & $1.85 \pm 0.87$ & $1.50 \pm 0.65$ \\
\hline$P$-value & & 0.06 & $0.02^{*}$ \\
\hline \multicolumn{4}{|c|}{ Foreign body sensation } \\
\hline Average & $3.35 \pm 0.63$ & $1.50 \pm 0.65$ & $0.71 \pm 0.72$ \\
\hline$P$-value & & $0.01^{*}$ & $0.01^{*}$ \\
\hline \multicolumn{4}{|l|}{ Dryness } \\
\hline Average & $2.64 \pm 1.15$ & $1.35 \pm 0.74$ & $0.5 \pm 0.65$ \\
\hline$P$-value & & $0.01^{*}$ & $0.01^{*}$ \\
\hline \multicolumn{4}{|l|}{ Discomfort } \\
\hline Average & $2.92 \pm 0.92$ & $2.21 \pm 0.80$ & $1.07 \pm 0.61$ \\
\hline$P$-value & & 0.08 & $0.01^{*}$ \\
\hline \multicolumn{4}{|c|}{ Sticky sensation } \\
\hline Average & $1.85 \pm 1.16$ & $2.21 \pm 1.05$ & $1.5 \pm 0.94$ \\
\hline$P$-value & & 0.194 & $0.021^{*}$ \\
\hline \multicolumn{4}{|l|}{ Pain } \\
\hline Average & $2.78 \pm 0.80$ & $1.78 \pm 0.89$ & $1.21 \pm 1.19$ \\
\hline$P$-value & & 0.080 & $0.04^{*}$ \\
\hline \multicolumn{4}{|l|}{ Tearing } \\
\hline Average & $2.57 \pm 0.93$ & $2.50 \pm 0.52$ & $2.28 \pm 1.13$ \\
\hline$P$-value & & 0.705 & $0.018^{*}$ \\
\hline \multicolumn{4}{|c|}{ Itching sensation } \\
\hline Average & $3.42 \pm 0.85$ & $2.07 \pm 1.21$ & $1.92 \pm 1.27$ \\
\hline$P$-value & & 0.080 & $0.04^{*}$ \\
\hline \multicolumn{4}{|c|}{ Burning sensation } \\
\hline Average & $2.35 \pm 1.28$ & $1.92 \pm 1.14$ & $1.35 \pm 1.08$ \\
\hline$P$-value & & 0.279 & $0.009^{*}$ \\
\hline \multicolumn{4}{|c|}{ Heavy sensation } \\
\hline Average & $2.78 \pm 0.69$ & $2.36 \pm 0.74$ & $2.36 \pm 0.74$ \\
\hline$P$-value & & 0.058 & $0.013^{*}$ \\
\hline \multicolumn{4}{|c|}{ Excessive blinking } \\
\hline Average & $1.50 \pm 1.22$ & $1.57 \pm 1.22$ & $1.21 \pm 1.05$ \\
\hline$P$-value & & 0.703 & 0.409 \\
\hline \multicolumn{4}{|c|}{ Uncomfortable in windy conditions } \\
\hline Average & $2.71 \pm 0.91$ & $2.00 \pm 0.55$ & $1.35 \pm 0.92$ \\
\hline$P$-value & & $0.01^{*}$ & $0.001^{*}$ \\
\hline \multicolumn{4}{|c|}{ Uncomfortable in very dry conditions } \\
\hline Average & $2.92 \pm 0.91$ & $2.14 \pm 0.86$ & $1.42 \pm 1.01$ \\
\hline$P$-value & & $0.026^{*}$ & $0.001^{*}$ \\
\hline
\end{tabular}

Data were analyzed using the Wilcoxon signed-rank test $\left({ }^{*} P<0.05\right.$ is considered statistically significant). 
Table 4 Tear meniscus amount using Fourier-domain optical coherence tomography at baseline and after treatment with cyclosporine A $0.05 \%$ (Restasis) twice per day for 3 months

\begin{tabular}{|c|c|c|c|}
\hline & First visit & After 1 month & After 3 months \\
\hline \multicolumn{4}{|c|}{ Tear meniscus height } \\
\hline Average & $185.15 \pm 13.93$ & $186.70 \pm 12.01$ & $186.55 \pm 12.82$ \\
\hline$P$-value & & 0.363 & 0.200 \\
\hline \multicolumn{4}{|c|}{ Tear meniscus depth } \\
\hline Average & $139.95 \pm 14.76$ & $140.75 \pm 14.15$ & $141.90 \pm 13.98$ \\
\hline$P$-value & & 0.168 & $0.019^{*}$ \\
\hline \multicolumn{4}{|c|}{ Tear meniscus angle } \\
\hline Average & $59.00 \pm 2.83$ & $59.65 \pm 2.32$ & $59.95 \pm 3.10$ \\
\hline$P$-value & & 0.197 & 0.064 \\
\hline \multicolumn{4}{|c|}{ Tear meniscus area } \\
\hline Average & $16975.35 \pm 2678.76$ & $16764.15 \pm 3403.26$ & $17051.85 \pm 3055.54$ \\
\hline$P$-value & & 0.280 & 0.157 \\
\hline
\end{tabular}

Data were analyzed using the Wilcoxon signed-rank test $\left({ }^{*} P<0.05\right.$ is considered statistically significant).

Allen $e a^{4}$ reported that prosthetic eye wearers did not produce as much tear fluid as people with normal eyes do. It was suggested that the mechanism of reduced tear production involved the absence of a corneal reflex.

Reflex tears supply most of the aqueous components of tears. The aqueous component is important in the selfcleansing mechanism of the normal eye. Thus, with too little aqueous component in the prosthetic eye, excessive proportions of mucin and oily components result. The thick mucoid residue causes ocular discomfort to many patients. In the normal conjunctiva, mucus produced by goblet cells form networks of strands that are broken into coarser strands with each blink. The aqueous component, together with the blink mechanism, removes the mucus strands. ${ }^{32}$ Decreased aqueous production on the dry surface of the ocular prosthesis inhibits this selfcleansing mechanism in the anophthalmic socket, leading to mucoid discharge. This is why many prosthetic eye wearers use aqueous lubricants for comfort. We could not conclude whether cyclosporine is superior to lubricants. This is because we intended to investigate the effect of cyclosporine on patients with a unilateral prosthetic eye through an intra-individual comparison between pre- and post-cyclosporine treatment. We believe that this issue should be investigated to justify the use of cyclosporine. As cyclosporine is more expensive than lubricants, comparative double blinded investigations in which lubricants are compared with topical cyclosporine for treating symptomatic artificial eye wearers are necessary to evaluate cost-effectiveness. ${ }^{33}$

Kim et $a l^{34}$ reported that decreased goblet cell density and an increased nucleus-to-cytoplasm ratio associated with squamous metaplasia resulted in decreased mucus production in anophthalmic patients wearing an ocular prosthesis. They attributed these cytological changes to the constant irritation of prolonged prosthesis wear. ${ }^{34}$ One investigation reported that cyclosporine had a normalizing effect on conjunctival squamous metaplasia and caused an increase in conjunctival goblet cell density. ${ }^{21}$ We did not undertake histological examinations regarding inflammation of the conjunctiva or quantitative analyses of inflammation-mediating substances. As the main results were based on patient-reported outcome measurement (PROM), further investigation using objective variables is needed.

However, the PROM data are still valuable because they were originally designed to assess treatment effectiveness in the context of clinical trials and are now more widely used to support decision making regarding the benefit of treatment. ${ }^{35}$

In conclusion, it was found that cyclosporine A $0.05 \%$ increased tear secretion and improved subjective symptoms in prolonged prosthesis wearers. However, due to the small sample and relatively short period of treatment ( 3 months), there are some limitations in demonstrating the clinical performance of cyclosporine A $0.05 \%$. Nevertheless, this study is the first to report that cyclosporine A $0.05 \%$ can help long-standing prosthetic eye wearers in relieving ocular discomfort. These results could be utilized as a basis for a larger and longer-term follow-up clinical study in terms of usage of topical cyclosporine in anophthalmic patients.

\section{Summary}

What was known before

- Prosthetic eye wearers frequently suffer from blepharitis and meibomian gland dysfunction.

- Recently, meibomian gland dysfunction can be treated effectively with cyclosporin A $0.05 \%$.

What this study adds

- Topical cyclosporin A $0.05 \%$ showed a satisfactory effect in long-standing prosthetic eye wearers with ocular discomfort.

\section{Conflict of interest}

The authors declare no conflict of interest.

\section{Acknowledgements}

We gratefully acknowledge the statistical support of Ji Sung Lee, Biostatistician, Biostatistical Consulting Unit, and Soonchunhyang University Medical Center. This study was supported by the Soonchunhyang University Research fund. 


\section{References}

1 Pine K, Sloan B, Stewart J, Jacobs RJ. Concerns of anophthalmic patients wearing artificial eyes. Clin Exp Ophthalmol 2011; 39: 47-52.

2 Rasmussen ML. Complications from eye prosthesis. Ugeskr Laeger 2008; 170: 2456-2458.

3 Arita R, Itoh K, Maeda S, Maeda K, Tomidokoro A, Amano S. Efficacy of diagnostic criteria for the differential diagnosis between obstructive meibomian gland dysfunction and aqueous deficiency dry eye. Jpn J Ophthalmol 2010; 54: 387-391.

4 Allen L, Kolder HE, Bulgarelli EM, Bulgarelli DM. Artificial eyes and tear measurements. Ophthalmology 1980; 87: 155-157.

5 Byun YS, Rho CR, Cho K, Choi JA, Na KS, Joo CK. Cyclosporine $0.05 \%$ ophthalmic emulsion for dry eye in Korea: a prospective, multicenter, open-label, surveillance study. Kor J Ophthalmol 2011; 25: 369-374.

6 Wilson SE, Perry HD. Long-term resolution of chronic dry eye symptoms and signs after topical cyclosporine treatment. Ophthalmology 2007; 114: 76-79.

7 Jang SY, Lee SY, Yoon JS. Meibomian gland dysfunction in longstanding prosthetic eye wearers. Br J Ophthalmol 2013; 97: 398-402.

8 Kim SE, Yoon JS, Lee SY. Tear measurement in prosthetic eye users with fourier-domain optical coherence tomography. Am J Ophthalmol 2010; 149: 602-607 e601.

9 DeBakey ME. Cyclosporin a: a new era in organ transplantation. Compr Ther 1984; 10: 7-15.

10 Kaswan RL, Salisbury MA, Ward DA. Spontaneous canine keratoconjunctivitis sicca. A useful model for human keratoconjunctivitis sicca: treatment with cyclosporine eye drops. Arch Ophthalmol 1989; 107: 1210-1216.

11 BenEzra D, Matamoros N, Cohen E. Treatment of severe vernal keratoconjunctivitis with cyclosporine A eyedrops. Transpl Proc 1988; 20: 644-649.

12 Kiang E, Tesavibul N, Yee R, Kellaway J, Przepiorka D. The use of topical cyclosporin A in ocular graft-versushost-disease. Bone Marrow Transplant 1998; 22: 147-151.

13 Diaz-Valle D, Benitez del Castillo JM, Castillo A, Sayagues O, Banares A, Garcia-Sanchez J. Immunologic and clinical evaluation of postsurgical necrotizing sclerocorneal ulceration. Cornea 1998; 17: 371-375.

14 Oh C, Apel AJ, Saville BA, Cheng YL, Rootman DS. Local efficacy of cyclosporine in corneal transplant therapy. Curr Eye Res 1994; 13: 337-343.

15 Sall K, Stevenson OD, Mundorf TK, Reis BL. Two multicenter, randomized studies of the efficacy and safety of cyclosporine ophthalmic emulsion in moderate to severe dry eye disease. CsA Phase 3 Study Group. Ophthalmology 2000; 107: 631-639.

16 Laibovitz RA, Solch S, Andriano K, O'Connell M, Silverman MH. Pilot trial of cyclosporine 1\% ophthalmic ointment in the treatment of keratoconjunctivitis sicca. Cornea 1993; 12: 315-323.

17 Stevenson D, Tauber J, Reis BL. Efficacy and safety of cyclosporin A ophthalmic emulsion in the treatment of moderate-to-severe dry eye disease: a dose-ranging, randomized trial. The Cyclosporin A Phase 2 Study Group. Ophthalmology 2000; 107: 967-974.
18 Pflugfelder SC, Jones D, Ji Z, Afonso A, Monroy D. Altered cytokine balance in the tear fluid and conjunctiva of patients with Sjogren's syndrome keratoconjunctivitis sicca. Curr Eye Res 1999; 19: 201-211.

19 Solomon A, Dursun D, Liu Z, Xie Y, Macri A, Pflugfelder SC. Pro- and anti-inflammatory forms of interleukin-1 in the tear fluid and conjunctiva of patients with dry-eye disease. Invest Ophthalmol Vis Sci 2001; 42: 2283-2292.

20 Brignole F, Pisella PJ, De Saint Jean M, Goldschild M, Goguel A, Baudouin C. Flow cytometric analysis of inflammatory markers in KCS: 6-month treatment with topical cyclosporin A. Invest Ophthalmol Vis Sci 2001; 42: 90-95.

21 Kunert KS, Tisdale AS, Gipson IK. Goblet cell numbers and epithelial proliferation in the conjunctiva of patients with dry eye syndrome treated with cyclosporine. Arch Ophthalmol 2002; 120: 330-337.

22 Qiao J, Yan X. Emerging treatment options for meibomian gland dysfunction. Clin Ophthalmol 2013; 7: 1797-1803.

23 Prabhasawat $P$, Tesavibul N, Mahawong W. A randomized double-masked study of $0.05 \%$ cyclosporine ophthalmic emulsion in the treatment of meibomian gland dysfunction. Cornea 2012; 31: 1386-1393.

24 Perry HD, Doshi-Carnevale S, Donnenfeld ED, Solomon R, Biser SA, Bloom AH. Efficacy of commercially available topical cyclosporine A $0.05 \%$ in the treatment of meibomian gland dysfunction. Cornea 2006; 25: 171-175.

25 Song JS, Oh J, Baek SH. A survey of satisfaction in anophthalmic patients wearing ocular prosthesis. Graefe's Arch Clin Exp Ophthalmol 2006; 244: 330-335.

26 Smith RE, Flowers Jr, CW. Chronic blepharitis: a review. CLAO J 1995; 21: 200-207.

27 Driver PJ, Lemp MA. Meibomian gland dysfunction. Surv Ophthalmol 1996; 40: 343-367.

28 Zengin N, Tol H, Gunduz K, Okudan S, Balevi S, Endogru H. Meibomian gland dysfunction and tear film abnormalities in rosacea. Cornea 1995; 14: 144-146.

29 McCulley JP, Shine WE. Meibomian secretions in chronic blepharitis. Adv Exp Med Biol 1998; 438: 319-326.

30 Enriquez-de-Salamanca A, Castellanos E, Stern ME, Fernandez I, Carreno E, Garcia-Vazquez C et al. Tear cytokine and chemokine analysis and clinical correlations in evaporative-type dry eye disease. Mol Vis 2010; 16: 862-873.

31 Lam H, Bleiden L, de Paiva CS, Farley W, Stern ME, Pflugfelder SC. Tear cytokine profiles in dysfunctional tear syndrome. Am J Ophthalmol 2009; 147: 198-205; e191.

32 Adams AD. The morphology of human conjunctival mucus. Arch Ophthalmol 1979; 97: 730-734.

33 Waduthantri S, Yong SS, Tan CH, Shen L, Lee MX Nagarajan $\mathrm{S}$ et al. Cost of dry eye treatment in an Asian clinic setting. PLoS ONE 2012; 7: e37711.

34 Kim JH, Lee MJ, Choung HK, Kim NJ, Hwang SW, Sung MS et al. Conjunctival cytologic features in anophthalmic patients wearing an ocular prosthesis. Ophthalmic plastic and reconstructive surgery 2008; 24: 290-295.

35 Dawson J, Doll H, Fitzpatrick R, Jenkinson C, Carr AJ. The routine use of patient reported outcome measures in healthcare settings. BMJ 2010; 340: c186. 